\title{
Prediction of Mental Health Problems among Higher Education Student Using Machine Learning
}

\author{
Nor Safika Mohd Shafiee \\ Faculty of Computer \& Mathematical Sciences, Universiti Teknologi MARA, 40450 Shah Alam, Selangor Darul Ehsan, \\ Malaysia \\ E-mail: pika.safika@gmail.com
}

\section{Sofianita Mutalib}

Faculty of Computer \& Mathematical Sciences, Universiti Teknologi MARA, 40450 Shah Alam, Selangor Darul Ehsan, Malaysia

Email: sofi@fskm.uitm.edu.my

Received:08 May 2020; Accepted: 13 Novermber 2020; Published: 08 December 2020

\begin{abstract}
Today, mental health problems become serious issues in Malaysia. In generally, mental health problems are health issues that effects on how a person feels, thinks, behaves, and communicate with others. According to National Health and Morbidity Survey (NHMS) 2017, one in five people in Malaysia is depression. Then, two in five people is anxiety and one in ten people is having stress. Higher education student also one of communities that have high risk to face mental health problems. The difficulties in identifying factors of mental health problems become a challenges and obstacle to help the person with mental health problem. Objectives of this paper are (1) review mental health problem among higher education student, (2) the contributing factors and (3) review the existing machine learning to analyse and predict mental health problem among higher education student. Finding of the paper will be used for other study to further discussion on mental health problems for implementation using computational modelling.
\end{abstract}

Index Terms: Mental health problems, Machine Learning

\section{Introduction}

One of problems that have been discover is difficulties in identifying the factors of mental health problems among the students. The factors can be influences by the biological, psychological and environment issues. A few symptoms and factors are similar which make diagnoses become complex and difficult that lead doctors to misjudge the problems [1]. The patient may receive incorrect treatments. This situation may increase the dangerous psychological patient condition that threaten both emotional and behavioural function patient (Elisabet, 2017).

The research paper is purposely to review mental health problem among higher education student and its contributing factors. It also reviews on the existing machine learning usage to analyse mental health problem among higher education student. Therefore, this research paper would share the exploration knowledge on the mental health problems among higher education students and the usage of machine learning in analysing the mental health problem.

In general, World Health Organization (WHO) define mental health problems or mental disorder as the combination of abnormal thoughts, emotions, behaviour and relationships with others [3]. Mental health problems can affect their daily activities and the relationship between people [4]. The present of machine learning would help in extraction of knowledge and it may improve the quality of medicine practices [5].

\section{Higher Education System In Malaysia}

In Malaysia, higher education system is fully responsible and operation by higher education institutions (HEIs) in Malaysia. It under the authority of the Ministry of Higher Education (MOHE) [6]. Higher education institution divided into two types which is public institution and private institution. There are 20 public institution and 447 private institution $[7,8]$. The different between these two institutions is the financial support for the institution. The public institution is government funded [9]. 
Furthermore, higher education consists of certificate, diploma, undergraduate and postgraduate [6]. There five level of higher education qualification; Certificate Level, Diploma Level, Bachelor's Degree Level, Master's Degree and Doctor of Philosophy (PhD) [6]. Usually, Certificate Level and Diploma Level are first destination for student with secondary school qualification which is Sijil Pelajaran Malaysia (SPM). Bachelor's Degree Level is qualified for student with diploma, postsecondary or pre-university qualifications. Next level is master's degree. It is for student further their study after bachelor's degree. Lastly, $\mathrm{PhD}$ is for student with a master's degree.

Based on statistic from Ministry of Education Malaysia, 552702 enrolled and 119345 students graduated from twenty Public Universities in Malaysia until 31st December 2018 [10]. It shows Malaysia is a developing country that emphasis on education. Malaysia target to develop more quality graduates is one of strategy for Malaysia to become a high-income country. Higher education important for a development country because to produce more professional workers in future. Higher education can give impact in economy sector and social environment especially in human development and move from poverty [11].

\section{Higher Education and Mental Health Problems}

Higher education refers to university life where a place to gain knowledge. University life is not easy to face the challenges and obstacle. But it not impossible for the student to success. Nowadays, the student grumble due to high stress level in university life. The stress level will be increasing towards the end of semester [12]. Most of the student experiences anxiety and depression at the end of semester compared to the beginning of semester [12] [13].

The level of stress increased in term of learning process because of the assessment, workload and examination period [12]. Besides that, there were other factors that affect the student mental health. On other hand, the students are facing high risk for mental health problems due to family problems, unclear vision of future career, financial and living away from home [14]. Furthermore, maintaining between university and other demand life also can lead the student face the risk of mental health problems [12].

Moreover, the student that has symptoms of mental health problems claimed that they do not receive any treatments and they would not seek for help regarding emotional problems. The student feels it is not important due to their friends have the same symptoms and it is normal in university life [13]. However, some of them aware that they need proper treatment, but they have low courage to seek for helps [13]. The negative stigma on the people with mental health problems also become the reason the students did not go for the treatment [13].

The stigma lead to discrimination or prejudice the people with mental health problem among the society [13]. Stigma on mental health problems give negative impact, so the student with mental health problem do not want to go treatment due to fear of being labelled by the society [13] [15]. Besides that, they think "this people" are sick, overly emotional and crazy [15]. Therefore, it is importance of the university consider new strategies to encourage student to get the right treatments for mental health problems.

\section{Mental Health Problem}

A mental health problem or mental illness is a health issues that affects the way on how a person feels, thinks, behaves, and communicate with others [16]. According to American Psychiatric Association, mental health problems or mental illness are emotional, thinking, behavioural or combination-related health conditions that are associated with social, work or family-related problems [17]. It can be concluded that mental health problem is health issues that affect the emotional, thinking, behavioural or communication with society. Therefore, daily activities also affect due to mental health problems. Example of mental health problems is anxiety, depression, stress, and Schizophrenia disorders [18]. The most common mental health problems occur in Malaysia are depression follow by anxiety and stress [19].

\section{A. Anxiety Disorder}

Anxiety disorders are the worry and fear overwhelming specially during face with big problems or in making big decision [20]. The life of people with anxiety disorder begins to be affected due to the anxiety disorder symptoms [21]. They feel extra nervousness, anxiousness, and involve excessive fear [22]. Besides that, they also face the symptoms such as racing heart, hard to breathe, feel sweaty, shaky or like want to vomit during the unpleasant situation [20]. 3Anxiety disorder is not restrict to any condition or age so everyone have possibility to face anxiety [22]. There are a few types of anxiety disorders such as Generalized Anxiety Disorder (GAD), panic disorder, social disorder and others.

People with GAD experience severe anxiety or stress about several things like personal safety, jobs, social interactions, and everyday life events, most days for at least 6 months [22]. People with GAD also like to avoid or seek reassurance about circumstances where the result is unpredictable, and to be unnecessarily concerned about things that might go wrong. [21]. Second, people with panic disorder can suddenly attacks of fear or anxiety, it also calls as panic attack [21] [22]. A panic attack is where the person suddenly becomes really frightened, having irregular pulse, sweating, shaking, feels shortness of breath, and sensations of being out of control [20,22].

Next, phobia-related disorders is an intense fear to specific objects or situations [20]. People with phobia-related 
disorder may have an irrational or unreasonable concern about a feared object or situation and they also try to avoid the situation [20]. Furthermore, specific phobia is excessive and persistent fear of a specific object, situation or activity that is generally not harmful for example heights, different animals (dog, spider or snake), and others situation or object [20] [22].

People with social anxiety disorder have an extreme general fear or anxiety about other people's negative judgment of attitudes or behaviours associated with their anxiety, causing them to feel embarrassed [20]. Besides that, they also avoid the situations where they think it might be the centre of attention or situation [21] [22]. Besides that, people with agoraphobia experience fear when they in situations where escape may be difficult or embarrassing, or help might not be available in the event of panic symptoms [20] [22]. People with agoraphobia are extremely afraid in two or more of the following situations; use of public transport, being in open spaces, being in enclosed spaces, standing in line or being in crowds \& being alone outside the house [20] [22].

People with anxiety disorder of separation are afraid to be separated from those they are attached to especially children [20]. However, adults also would have separation disorder [22]. If separation is happening or would be happen, they could create the hallucinations about separating themselves from attachment figures [20]. They may have nightmares about the separated experience [22]. Besides that, they also may experience physical symptoms of distress often build during their childhood. The symptoms can carry through adulthood [22].

\section{B. Depression Disorder}

Depression disorders been characterized by sadness, loss of interest or excitement, feelings of guilt or low self-worth, disturbed sleep or appetite, feelings of tiredness, and poor concentration [22]. According to National Institute of Health Mental, depression or clinical depression is serious mood disorder that cause severe symptoms that affect the ways of feel, think and handle daily activity [23]. Besides that, depression can cause pain for the person with depression and people surrounding. It can be a serious health condition because it may lead to suicide [24]. The signs and symptoms of depression are constantly sad, feel "empty", feel hopelessness loss of interest in hobbies and activities, feel tired and etc [23]. There are several types of depression disorders such as persistent depressive disorder, postpartum depression and psychotic depression [24].

Persistent depressive disorder or called as dysthymia is a depressed mood that lasts for at least two years [24]. An individual who been diagnosed with persistent depressive disorder may have major depression episodes along with periods of less severe symptoms, but signs must last two years in order to be considered persistent depressive disorder [24]. Postpartum depression is a mild symptom of depression and anxiety experienced after birth by many mothers. They feel overwhelmingly sad nervous, and drained. The effect that the person with postpartum depression has on themselves and/or their babies is having difficulty managing daily care activities [24].

Psychotic depression happens when a person has severe depression with form of psychosis, such as disturbing false fixed beliefs or hearing or seeing disturbing things that others are unable to hear or see. The symptoms of psychotic typically have a depressive "theme," such as delusions of guilt, poverty, or illness [24]. Usually, the development of depression of seasonal affective disorder is defined in winter months when less natural sunlight is available [24]. Winter depression, usually accompanied by social isolation, increasing sleep and increased weight, is predicted to revert annually to seasonal affective disorder.

Someone who has bipolar disorder experiences extremely low mood episodes that meet the major depression characteristics. However, a person with bipolar disorder often experiences extreme high moods called "mania" or a less severe form called "hypomania," either euphoric or irritable [24].

\section{Factors of Mental Health Problems}

All the factors listed are based on correlation or regression result in previous research paper. Generally, the factors of mental health problems are based on biological factor, social environment, and socioeconomic environments [25]. Biological factor in mental health problems is referring to abnormal functioning of nerve cell circuits or pathways that connect brain regions [26]. The factors of mental health problem in term of biological are genetic, infection that linked to brain damage, brain defect, prenatal damage and other factors. For example, several mental health problems association with low birth weight especially in schizophrenia [25].

Social environment refers to how a person interact with the environment surrounded and their culture or way of life. It is about relationship between the family, friends, officemates and local society [27]. Example of social environment factor is lack of social support and discrimination at workplaces. While socioeconomic is reflecting the financial status of the person. Financial problems become the main factors of mental health problems. Usually, when people having low financial situation, they attend to be stress and anxious [27].

Table 1 shows the comparison factors of mental health problems among higher education student. The main factors of mental health problems among higher education student are lack of social support [12] [28] [30] [32] [33], financial problems [12] [28] [30] [31] [34] and learning environment [12] [28] [30] [34] [35], five out of ten research paper concluded it. Lack of social support related with mental health problem because having insufficient social support resulted in an increase in stress [12]. Learning environment is referring to university life, assessment and learning style. 
Other factors are being a female, far from home, family problem, childhood adversities, LGBT non-white and internet addition [27] [28] [31] [35]. Based on the comparison table, most of the research is based on medical field such as nurse, pharmacy and doctor. This is show that medical have the high risk for mental health problem.

Table 1. Comparison Factor of Mental Health among Higher Education Student

\begin{tabular}{|c|c|c|c|c|c|c|c|c|c|c|c|c|}
\hline & Fact & of $n$ & al he & & & & & & & & & \\
\hline Tittle & 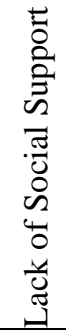 & 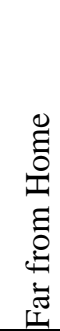 & 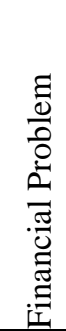 & 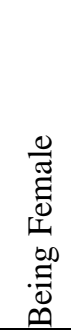 & 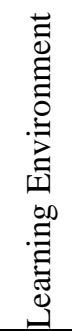 & 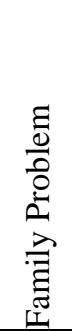 & 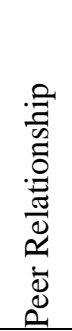 & 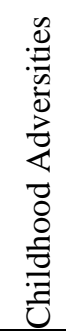 & 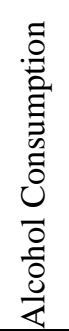 & 䛼 & 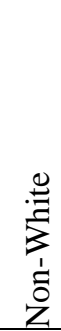 & 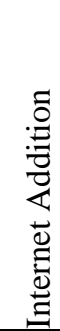 \\
\hline [20] & 1 & & 1 & 1 & 1 & & & & & & I & \\
\hline [30] & 1 & 1 & 1 & & 1 & & 1 & & & & & \\
\hline [19] & & & & & & & & I & & 1 & & \\
\hline [21] & & & & 1 & & & & & & & & \\
\hline [31] & & & I & 1 & & 1 & & & & & & I \\
\hline [32] & 1 & & & 1 & & & & & & & & \\
\hline [33] & 1 & & & & & & 1 & & 1 & & & \\
\hline [34] & & & 1 & & I & 1 & & & & & & \\
\hline [35] & & & & & 1 & & & & & & & 1 \\
\hline [13] & I & I & 1 & & 1 & I & I & & & & & \\
\hline
\end{tabular}

\section{Machine learning}

Machine learning is scientific discipline that focus on how computers learn or in other word gain knowledge from data [5]. Machine learning also define as field of study that gives computers the capability to learn without being explicitly programmed [5]. The machine learning divided into four categories which is supervised learning, unsupervised learning, semi-supervised learning and reinforcement learning [36].

\section{A. Supervised Learning}

Supervised learning occurs when an algorithm learns from sample data and associated target responses that can consist of numeric values or string labels, such as classes or tags, in order to later predict the correct response when posed with new examples [37]. In supervised learning, there has target variables in training dataset that called label and it is output vector [36]. The analogy of supervised learning is a teacher give many examples based on one topic for the student to memories and the student derives general rules from these examples. There are two groups of algorithms under supervised learning. They are regression and classification [36].

Algorithms for regression are linear regression and logistic regression. Linear regression is statistical tool for modelling the relationship between some "explanatory" variables and some real valued outcome [37] [38]. While, logistic regression purposely to describe the relationship between one dependent binary variable or more nominal, ordinal, interval or ratiolevel independent variables [38] [39]. Algorithms for classification are decision trees, Support Vector Machines (SVM), Naive Bayes, K-Nearest Neighbors (KNN), Random Forest, and Artificial Neural Networks (ANN) [38] [40] [41].

Decision tree is classification based on a set of if-then rules [38]. SVM is a classifier which finds an optimal hyperplane to categorize the data while naïve Bayes based on statistical learning approach [38]. KNN uses feature similarity to assign new point value by using uses various distance functions such as Euclidean distance, Hamming distance, and moreover [38]. Random forest is an algorithm with a collection of trees and each tree in the forest gives a classification [38]. ANN is based on the model of a human neuron for classifying the data [38]. 
Fig.1: Taxonomy of Machine Learning Techniques

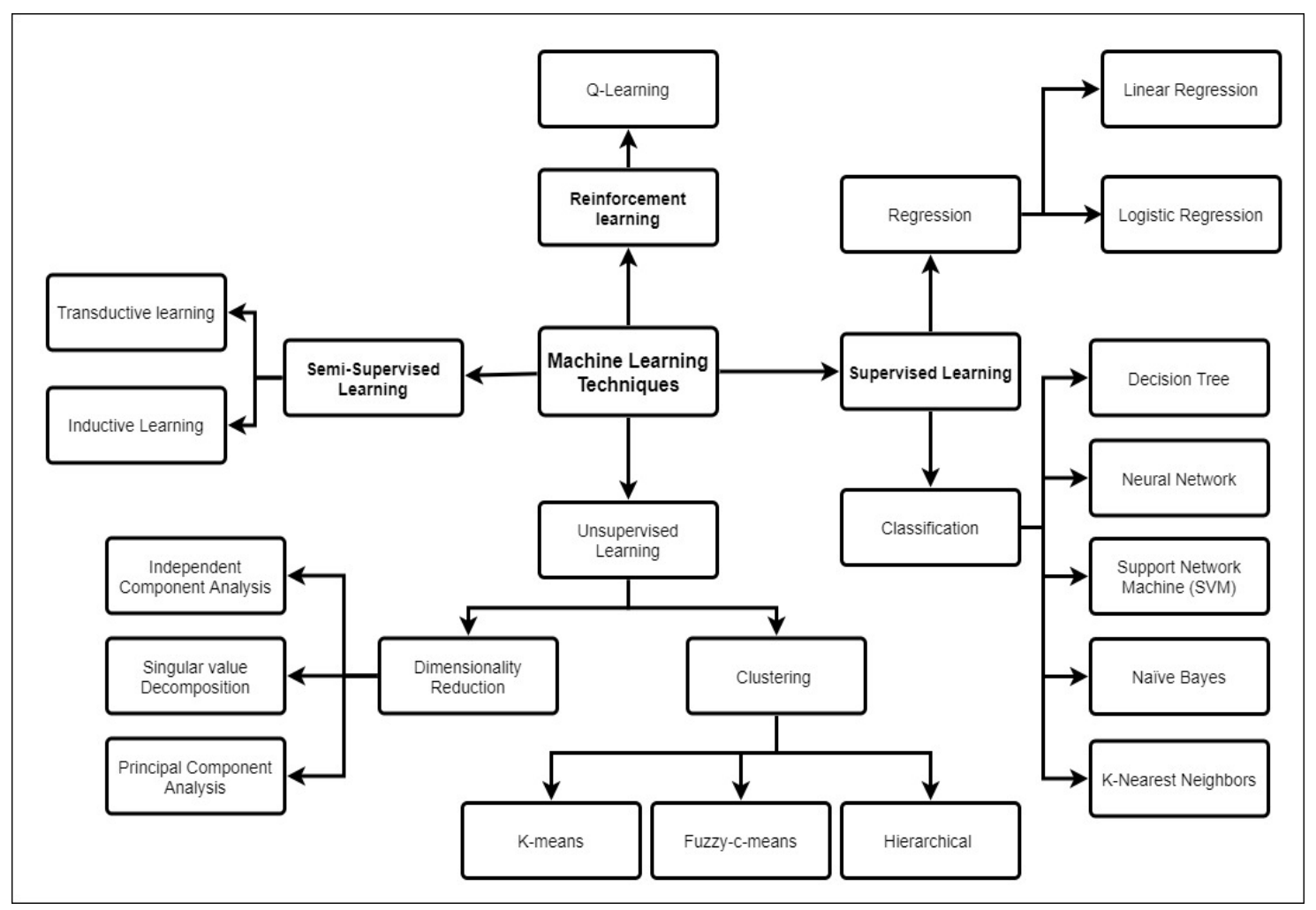

\section{B. Unsupervised Learning}

Unsupervised learning occurs when an algorithm learns from simple examples without any correspondent response, it therefore allows the algorithm to evaluate individual data patterns [37]. Unsupervised learning is lack of supervisor or target variables in training dataset. The algorithm will solve this problem by find the similarities between one case with the others. Unsupervised learning is like classify type of chili that based on observation in terms of size, colour, tastes and degree of spice. The classification of chili based on the degree of similarity. The algorithm under unsupervised learning is clustering and dimensionality reduction [38] [42].

Algorithms for clustering are k-means, hierarchical and fuzzy-c-means [38]. K-means is based on the number of random locations $(\mathrm{K})$ and all the remaining points associated with the nearest centres [38]. Hierarchical clustering technique groups the similar objects into clusters that have a predetermined top-down or bottom-up order [38]. Fuzzy-cmean is assigning the observation to one or more clusters [38]. Algorithms for dimensionality reduction are principal component analysis (PCA), singular value decomposition (SVD) and independent component analysis (ICA) [38]. PCA is a multivariate analysis feature extraction method. SVD is a matrix factorization method used to reduce the dimensionality. ICA is finding a new basis for data representation and decomposes multivariate observations into additive subcomponents [38].

\section{Semi-Supervised Learning}

Next, semi-supervised learning (SSL). This type of learning techniques is based on mixture classified and unclassified data [36]. It is half supervised and half unsupervised learning. The goals of SSL to tackle both disadvantages supervised and unsupervised learning. SLL could produce better insight because an unlabelled data patterns along with labelled data pattern improve the accuracy when it compared with supervised and unsupervised learning [43]. SSL divided into two categories which is transductive learning and inductive semi-supervised learning [38]. Transductive learning is purposely to predict the exact labels for unlabel data [38]. While Inductive semi-supervised produce labels for unlabelled data and produce classifier at the same time.

\section{Reinforcement Learning}

Lastly, reinforcement learning is learning methods that using observation gathered from the interaction with the environment to take actions that would maximize the reward or minimize the risk [44]. Reinforcement learning is learned from various observation cases include the errors or false cases. It learns from mistake to improve the knowledge of the 
model. The example of reinforcement learning application is having the gamer stuck in a maze while avoiding an enemy [45]. This program lets the algorithm know the result of the action and learns to stop what it considers to be risky and to survive [45]. Q-learning technique is one model-free reinforcement learning approach where each agent interacts with the environment and generate sequence of observation as state-action-reward [45].

\section{E. Machine Learning Tool}

Generally, data mining tool is software or language used to performances data mining techniques. The blooming data mining techniques that lead many organizations develop data mining tools. The variety data mining tool lead to competence of data mining issues. According to Wang and Chen (2015), data mining tool competence refers to the data mining possibility tools in completing a series of tasks like data preparation, data analysis and result evaluation [44]. A good data mining tool is based on the seven aspects, which is basic competence, data access, data pre-processing, data mining tasks completion, realization of data mining algorithm, model interpretation, evaluation, and visualization [44].

Three example of data mining tool is:

\section{i. Python}

Python is an object-oriented programming that give more advantages to the users [45]. Pythons is a general-purpose language. It can build anything using Python. Besides that, it is a great for backend web development, data analysis, artificial intelligence and scientific computing [46]. Pythons syntax come along with modules and package to support the task. The module and package encourage program modularity and code reuse, so very suitable for Rapid Application Development [43]. It simple, easy to learn the syntax and very flexible [45,46].

\section{ii. RapidMiner}

RapidMiner is a tool that provides an integrated environment for machine learning, data mining, text mining, predictive analytics and business analytics [47]. RapidMiner is easy to use because it has interactive environment, graphical design helps the user build model in easiest way [48]. Transformation data and model building using the operator so it easy to be understand and can be reusable many times [47]. Along the process, RapidMiner give suggestion on operator recommender for next steps.

\section{iii. R Language}

$\mathrm{R}$ language is a language and environment for statistical computing and graphics [49]. It provides a various of statistical method and model, for example linear and nonlinear modelling, classical statistical tests, classification and moreover [49]. It is highly extensible. $\mathrm{R}$ can be use as programming, transforming, discovering, modelling and communicate the results [50]. The collection of library and package helps in transforming data, modelling and produce output visualization [49].

\section{Discussion}

Firstly, the main factors of mental health problems among higher education student are lack of social support [13] [20] [30] [32] [33], financial problems [13] [20] [30] [31] [34] and learning environment [13] [20] [30] [34] [35], five out of ten research paper concluded it. Lack of social support related with mental health problem because having insufficient social support resulted in an increase in stress [13]. The support from family, members and people surrounding can give positive impact to a person. Without social support, the student will loneliness and increase their level of stress. It can lead to mental health problems such as depression and anxiety disorder.

Financial problem and mental health problems among student has the relationship with the scholarships and education loan. The student feel burden when they need to maintain their performances in order to main the scholarship for the next semester [19]. If the student has poor academic performances, the scholarship will be cut off or the amount will be reduced. Learning environment is referring to university life, assessment and learning style. Maintaining between university and other demand life is one of the factors the student faced mental health problems. Besides that, the level of stress among student will increase towards the end of the semester specially during the examination period [13].

Based on table 2, supervised learning is the most selected data mining techniques to solve the problems regarding mental health problems classification. The most famous algorithm used is support vector machine (SVM) and followed by decision tree and neural network. These three models have high accuracy which is above $70 \%$. These three models have good generalization capabilities which prevent it from over-fitting. 
Table 2 Summary of Previous Research on Data Mining Techniques used in Mental Health Problems

\begin{tabular}{|c|c|c|c|c|}
\hline Author & Techniques & Variables & Tool & Significances \\
\hline [31] & $\begin{array}{l}\text { Random } \\
\text { forest, NB, } \\
\text { SVM, KNN }\end{array}$ & $\begin{array}{l}\text { Perceived Stress Scale } \text { (PSS) } \\
\text { questionnaire }\end{array}$ & $\begin{array}{l}\text { Not } \\
\text { stated }\end{array}$ & $\begin{array}{l}\text { The accuracy of random forest } 83.33 \% \text {, } \\
\text { NB } 71.42 \% \text {, SVM } 85.71 \% \text { and KNN } \\
55.55 \%\end{array}$ \\
\hline [51] & $\begin{array}{l}\text { DT, SVM, } \\
\text { ANN, BN }\end{array}$ & $\begin{array}{l}\text { Outgoing activity, toileting activity, } \\
\text { sleeping activity, disease, mental } \\
\text { status (GDS) }\end{array}$ & $\begin{array}{l}\text { Not } \\
\text { stated }\end{array}$ & $\begin{array}{l}\text { Normal: DT } 95.1 \% \text {, SVM } 75.6 \% \text {, ANN } \\
\text { 96.7\%, BN 92.7\% } \\
\text { Mild depression: DT 94.3\%, SVM } \\
\text { 75.6\%, ANN 96.2\%, BN } 91.3 \% \\
\text { Severe depression: DT } 99.4 \% \text {, SVM } \\
\text { 99.5\%, ANN \& BN } 100 \%\end{array}$ \\
\hline [52] & $\begin{array}{ll}\text { KNN, } & \text { SVM } \\
\text { BN } & \end{array}$ & $\begin{array}{l}\text { Depression level, sex, grade, major, } \\
\text { technical, novel, amusing, } \\
\text { psychological, }\end{array}$ & SPSS & $\begin{array}{l}\text { The accuracy of KNN } 76.6 \% \text {, SVM } \\
82 \% \text {, NB } 64.2 \%\end{array}$ \\
\hline [53] & $\begin{array}{l}\text { Random } \\
\text { forest, } \\
\text { random tree, } \\
\text { MLP, SVM } \\
\end{array}$ & $\begin{array}{l}\text { Age, MMSE score, neurological } \\
\text { condition, depression (GDS), MoCA } \\
\text { test }\end{array}$ & WEKA & $\begin{array}{l}\text { The accuracy of random forest } 95.45 \% \text {, } \\
\text { random tree 93.93\%, MLP } 92.42 \% \text {, } \\
\text { SVM } 92.42 \%\end{array}$ \\
\hline [54] & XGBoost & $\begin{array}{l}\text { socio-demographic information, } \\
\text { earthquake-related experience, sleep, } \\
\text { mood, } \\
\text { somatic symptoms and everyday } \\
\text { functioning were assessed, CRIES }\end{array}$ & Python & $\begin{array}{l}\text { The combination of earthquake } \\
\text { experience, everyday functioning, } \\
\text { somatic symptoms and sleeping } \\
\text { correctly predicted } 683 \text { out of } 802 \text { cases } \\
\text { of probable PTSD, translating to a } \\
\text { classical accuracy of } 74.476 \% \\
\text { ( } 85.156 \% \text { sensitivity and } 60.366 \% \\
\text { specificity) and an area under the curve } \\
\text { of } 0.80 \text {. }\end{array}$ \\
\hline [55] & $\begin{array}{l}\text { SVM, Linear } \\
\text { Discriminant } \\
\text { analysis, } \\
\text { ensemble, } \\
\text { KNN, DT }\end{array}$ & $\begin{array}{l}\text { Mean heart rate, } \\
\text { Standard deviation of heart rate, } \\
\text { Mean EDA, Standard deviation of } \\
\text { EDA, Minimal EDA, Maximal EDA, } \\
\text { Root mean square EDA, Mean ECG, } \\
\text { Standard deviation of ECG, Energy } \\
\text { of ECG, Absolute value of ECG, } \\
\text { Root mean square ECG }\end{array}$ & $\begin{array}{l}\text { MATL } \\
\text { AB }\end{array}$ & $\begin{array}{l}\text { The accuracy of SVM 91\%, Linear } \\
\text { Discriminant Analysis } 90.7 \% \text {, ensemble } \\
89.5 \% \text {, KNN } 87.6 \% \text {, DT } 86.1 \%\end{array}$ \\
\hline
\end{tabular}

\section{Conclusion}

This paper share about the mental health problems among higher education student. Different research papers have been compared in order to determine the research gaps. Review on mental health problem among higher education student and the contributing factors give the illustration on what is happening to the student with mental health problems. Moreover, it gives more information on the factors of mental health problems among the student. The most common factors have been identified which is lack social support, financial problem and learning environment. Lastly, the supervised learning techniques most popular is Support Vector Machine (SVM). Almost all the research papers listed in table 2 used SVM algorithm. In addition, SVM has high accuracy between 70\% to $96 \%$.

\section{References}

[1] Khan, Shahidul \& Islam, Ariful \& Hossen, Akther \& Zahangir, Taiyeb \& Latiful Haque, Abu. (2018). Supporting the Treatment of Mental Diseases using Data Mining. 339-344. 10.1109/ICISET.2018.8745591. Parekh, R. (2018). What Is Mental Illness? Retrieved from https://www.psychiatry.org/patients-families/what-is-mental-illness

[2] Kvarnstrom, E. (2017, August 4). The Dangers of Mental Health Misdiagnosis: Why Accuracy Matters. Bridges to Recovery. https://www.bridgestorecovery.com/blog/the-dangers-of-mental-health-misdiagnosis-why-accuracy-matters/

[3] Sakinah (2019). Malaysian Teens Are Suffering from Mental Health Problems. Retrieved from https://www.easyuni.my/en/advice/malaysian-teens-mental-health-2444/

[4] Deo, R. C. (2015). Machine learning in medicine. Circulation, 132(20), 1920-1930. https://doi.org/10.1161/CIRCULATIONAHA.115.001593 3 .

[5] StudyMalaysia.com (2015), The Malaysian Higher Education System - An Overview. Retrieved from
https://www.studymalaysia.com/education/higher-education-in-malaysia/the-malaysian-higher-education-system-an-overview

[6] Jabatan Pendidikan Tinggi (JPT) (2017). "Direktori Universiti Awam”. Retrieved from http://jpt.mohe.gov.my/portal/ipta/institusi-pendidikan-tinggi-awam/direktori-universiti-awam

[7] Pejabat Ketua Pengarah Pendidikan Tinggi (2014). Senarai Daftar IPTS. 
[8] Education Malaysia (n.d.) Malaysia Higher Education in Brief. Retrieved from https://educationmalaysia.gov.my/malaysiahigher-education-in-brief/

[9] Malaysia Educational Statistics (2019). Educational Planning and Research Division MINISTRY OF EDUCATION MALAYSIA with Best Compliments.

[10] Akareem, H. S., \& Hossain, S. S. (2016). Determinants of education quality: what makes students' perception different? Open Review of Educational Research, 3(1), 52-67. https://doi.org/10.1080/23265507.2016.1155167

[11] Pitt, A., Oprescu, F., Tapia, G., \& Gray, M. (2018). An exploratory study of students' weekly stress levels and sources of stress during the semester. Active Learning in Higher Education, 19(1), 61-75. https://doi.org/10.1177/1469787417731194

[12] McLafferty, M., Lapsley, C. R., Ennis, E., Armour, C., Murphy, S., Bunting, B. P., ... O’Neill, S. M. (2017). Mental health, behavioural problems and treatment seeking among students commencing university in Northern Ireland. PLoS ONE, 12(12), 114. https://doi.org/10.1371/journal.pone.0188785

[13] Shannon, S., Breslin, G., Haughey, T., Sarju, N., Neill, D., Lawlor, M., \& Leavey, G. (2019). Predicting Student-Athlete and Non-Athletes’ Intentions to Self-Manage Mental Health: Testing an Integrated Behaviour Change Model. Mental Health and Prevention, 13(January), 92-99. https://doi.org/10.1016/j.mhp.2019.01.006

[14] Vidourek, R. A., \& Burbage, M. (2019). Positive mental health and mental health stigma: A qualitative study assessing student attitudes. Mental Health and Prevention, 13(October 2018), 1-6. https://doi.org/10.1016/j.mhp.2018.11.006

[15] Department of Health of Australian Government (2017). What is mental illness? Retrieved from https://www1.health.gov.au/internet/publications/publishing.nsf/Content/mental-pubs-w-whatmen-toc mental-pubs-wwhatmen-what

[16] American Psychiatric Association (APA) (n.d.). What Is Mental Illness? Retrieved from https://www.psychiatry.org/patientsfamilies/what-is-mental-illness

[17] Newman. T (2017, August 24) What is mental health? Retrieved from https://www.medicalnewstoday.com/articles/154543.php

[18] Institute for Public Health (IPH). (2018). National Health and Morbidity Survey (NHMS) 2017: Key Findings from the Adolescent Health and Nutrition Surveys; Infographic Booklet. National Health and Morbidity Survey (NHMS) 2017, (April), 29.

[19] National Institute of Mental Health (NIMH) (n.d.). Anxiety Disorder. Retrieved from https://www.nimh.nih.gov/health/topics/anxiety-disorders/index.shtml

[20] Andrews, G., Bell, C., Boyce, P., Gale, C., Lampe, L., Marwat, O., ... Wilkins, G. (2018). Royal Australian and New Zealand College of Psychiatrists clinical practice guidelines for the treatment of panic disorder, social anxiety disorder and generalised anxiety disorder. Australian and New Zealand Journal of Psychiatry, 52(12), 1109-1172. https://doi.org/10.1177/0004867418799453

[21] Parekh, R. (2017). What Are Anxiety Disorders? Retrieved from psychiatry.org/patients-families/anxiety-disorders/what-areanxiety-disorders

[22] World Health Organization (WHO). (2017). Depression and Other Common Mental Disorders - Global Health Estimation. Obstetrics and Gynecology, 48(1), 56-60.

[23] National Institute of Health Mental (NIHM), (n.d.). Depression. Retrieved from https://www.nimh.nih.gov/health/topics/depression/index.shtml

[24] WebMD (n.d.). Causes of Mental Illness. Retrieved from https://www.webmd.com/mental-health/mental-health-causes-mentalillness\#1

[25] World Health Organization (WHO), (2019). Depression. Retrieved from https://www.who.int/news-room/factsheets/detail/depression

[26] O’Neill, S., McLafferty, M., Ennis, E., Lapsley, C., Bjourson, T., Armour, C., ... Murray, E. (2018). Socio-demographic, mental health and childhood adversity risk factors for self-harm and suicidal behaviour in College students in Northern Ireland. Journal of Affective Disorders, 239(May), 58-65. https://doi.org/10.1016/j.jad.2018.06.006

[27] Moutinho, I. L. D., Lucchetti, A. L. G., Ezequiel, O. da S., \& Lucchetti, G. (2019). Mental health and quality of life of Brazilian medical students: Incidence, prevalence, and associated factors within two years of follow-up. Psychiatry Research, 274(January), 306-312. https://doi.org/10.1016/j.psychres.2019.02.041

[28] Burger, P. H. M., \& Scholz, M. (2018). Gender as an underestimated factor in mental health of medical students. Annals of Anatomy, 218, 1-6. https://doi.org/10.1016/j.aanat.2018.02.005

[29] Alyousef, S. M. (2019). Psychosocial stress factors among mental health nursing students in KSA. Journal of Taibah University Medical Sciences, 14(1), 60-66. https://doi.org/10.1016/j.jtumed.2018.11.006

[30] Guofeng, D., \& Yuming, X. (2009). Internet addiction and mental health status of Chinese college freshmen. 3rd International Conference on Bioinformatics and Biomedical Engineering, ICBBE 2009, (August) https://doi.org/10.1109/ICBBE.2009.5162977

[31] Sabourin, A. A., Prater, J. C., \& Mason, N. A. (2019). Assessment of mental health in doctor of pharmacy students. Currents in Pharmacy Teaching and Learning, 11(3), 243-250. https://doi.org/10.1016/j.cptl.2018.12.004

[32] Sæther, S. M. M., Knapstad, M., Askeland, K. G., \& Skogen, J. C. (2019). Alcohol consumption, life satisfaction and mental health among Norwegian college and university students. Addictive Behaviors Reports, 10(March), 100216. https://doi.org/10.1016/j.abrep.2019.100216

[33] Zahir Izuan, A., Shamsul Azhar, S., Tan, M. K. S., \& Syed-Sharizman, S. A. R. (2018). Neighbourhood influences and its association with the mental health of adolescents in Kuala Lumpur, Malaysia. Asian Journal of Psychiatry, 38(July), 35-41. https://doi.org/10.1016/j.ajp.2018.10.018

[34] Ahuja, R., \& Banga, A. (2019). Mental stress detection in university students using machine learning algorithms. Procedia Computer Science, 152, 349-353. https://doi.org/10.1016/j.procs.2019.05.007

[35] Mohssen Mohammad, Muhammad Badruddin Khan, E. B. M. B. (2017). Algorithms and Applications. In CRC Press (Vol. 7). https://doi.org/10.1007/978-94-017-2221-6_5

[36] Machine Learning: From Theory to Algorithms (Vol. 9781107057135). https://doi.org/10.1017/CBO9781107298019 
[37] Praveen Kumar, D., Amgoth, T., \& Annavarapu, C. S. R. (2019). Machine learning algorithms for wireless sensor networks: A survey. Information Fusion, 49(April 2018), 1-25. https://doi.org/10.1016/j.inffus.2018.09.013

[38] StatisticsSolutions (n.d.). What is Logistic Regression? Retrieved from https://www.statisticssolutions.com/what-is-logisticregression/

[39] Sharda.R, Delen.D, Turban.E. (2014). Business Intelligence and Analytic System for Decision Support 10th Edition: England: Pearson Education Limited

[40] Garcia-Ceja, E., Riegler, M., Nordgreen, T., Jakobsen, P., Oedegaard, K. J., \& Tørresen, J. (2018). Mental health monitoring with multimodal sensing and machine learning: A survey. Pervasive and Mobile Computing, 51, 1-26. https://doi.org/10.1016/j.pmcj.2018.09.003

[41] Pierson, L. (2017) Data Science For Dummies, 2nd Edition: Canada: John Wiley\& Sons, Inc

[42] C A Padmanabha Reddy, Y., Viswanath, P., \& Eswara Reddy, B. (2018). Semi-supervised learning: a brief review. International Journal of Engineering \& Technology, 7(1.8), 81. https://doi.org/10.14419/ijet.v7i1.8.9977

[43] Wang, X. H., \& Chen, C. A. (2015). Research on competence evaluation system of data mining tools. 2015 IEEE International Conference on Mechatronics and Automation, ICMA 2015, 1-5. https://doi.org/10.1109/ICMA.2015.7237446

[44] DataCamp (2018). Python Object-Oriented Programming (OOP): Tutorial. Retrieved from https://www.datacamp.com/community/tutorials/python-oop-tutorial

[45] Codementor (2018). Why Learn Python? Retrieved from http://www.bestprogramminglanguagefor.me/why-learn-python

[46] Oliveira, C., Guimarães, T., Portela, F., Santos, M., Oliveira, C., Guimarães, T., ... Santos, M. (2019). Benchmarking Business Analytics Techniques in Big Data. Procedia Computer Science, 160, 690-695. https://doi.org/10.1016/j.procs.2019.11.026

[47] RapidMiner (n.d.). RapidMiner Studio - Visual workflow designer for the entire analytics team. Retrieved from https://rapidminer.com/products/studio/

[48] R Foundation(n.d.). What is R? Retrieved from r-project.org/about.html

[49] Spyrou, I. M., Frantzidis, C., Bratsas, C., Antoniou, I., \& Bamidis, P. D. (2016). Geriatric depression symptoms coexisting with cognitive decline: A comparison of classification methodologies. Biomedical Signal Processing and Control, 25, 118-129. https://doi.org/10.1016/j.bspc.2015.10.006

[50] Kim, J. Y., Liu, N., Tan, H. X., \& Chu, C. H. (2017). Unobtrusive Monitoring to Detect Depression for Elderly with Chronic Illnesses. IEEE Sensors Journal, 17(17), 5694-5704. https://doi.org/10.1109/JSEN.2017.2729594

[51] Hou, Y., Xu, J., Huang, Y., \& Ma, X. (2017). A big data application to predict depression in the university based on the reading habits. 2016 3rd International Conference on Systems and Informatics, ICSAI 2016, (Icsai), $1085-1089$. https://doi.org/10.1109/ICSAI.2016.7811112

[52] Spyrou, I. M., Frantzidis, C., Bratsas, C., Antoniou, I., \& Bamidis, P. D. (2016). Geriatric depression symptoms coexisting with cognitive decline: A comparison of classification methodologies. Biomedical Signal Processing and Control, 25, 118-129. https://doi.org/10.1016/j.bspc.2015.10.006

[53] Ge, F., Li, Y., Yuan, M., Zhang, J., \& Zhang, W. (2019). Identifying predictors of probable posttraumatic stress disorder in children and adolescents with earthquake exposure: A longitudinal study using a machine learning approach. Journal of Affective Disorders, (September). https://doi.org/10.1016/j.jad.2019.11.079

[54] Hasanbasic, A., Spahic, M., Bosnjic, D., Adzic, H. H., Mesic, V., \& Jahic, O. (2019). Recognition of stress levels among students with wearable sensors. 2019 18th International Symposium INFOTEH-JAHORINA, INFOTEH 2019 - Proceedings, (March), 20-22. https://doi.org/10.1109/INFOTEH.2019.8717754

\section{Authors' Profiles}

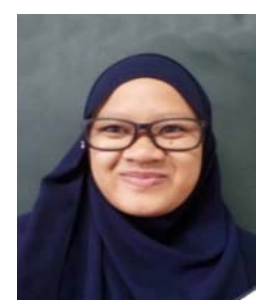

Nor Safika Mohd Shafiee is a student from Master of Data Sciences in Universiti Teknologi Mara. She received her BSc degree of Business Computing in 2019 from the same university.

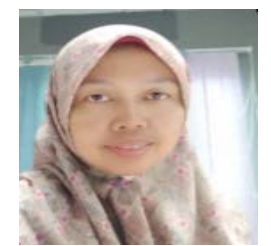

Sofianita Mutalib is a senior lecturer in Faculty of Computer and Mathematical Sciences in Universiti Teknologi Mara. She received a master's degree in Information Technology in Universiti Kebangsaan Malaysia in 1998. She teaches courses related to data mining, special topics in Artificial Intelligence, knowledge based system and Intelligent System Development. Her primary research interests involve the intelligent systems, data mining and machine learning

How to cite this paper: Nor Safika Mohd Shafiee, Sofianita Mutalib. " Prediction of Mental Health Problems among Higher Education Student Using Machine Learning ", International Journal of Education and Management Engineering (IJEME), Vol.10, No.6, pp.1-9, 2020. DOI: 10.5815/ijeme.2020.06.01 